\section{Fernando Pessoa dramatista: apontamentos sobre o background teatral do autor}

RODRIGO XAVIER

The outset of this study befalls from the presence of some dramatic works at Fernando Pessoa's private library, and discusses the reception of those texts through the side notes analysis as well as the critical fragments and texts written by the poet about those pieces and its respective authors. The present work intends to present the impressions resulting from the first phase of an ongoing investigation around the poet's literary background regarding the universe of drama and its respective critical fortune. The main hypothesis surrounding this investigation is that Pessoa could have grasped some elements - such as lyricism, tragic, inertia, symbolism, subjectivism - presented through these pieces in order to build his perspective as a dramatic poet.

FERNANDO PESSOA / J. W. VON GOETHE / MAURTCE MAETERLINCK / WILLIAM SHAKESPEARE

\section{CONSIDERAÇÕES INICIAIS E ESTADO DA QUESTÃO}

O background intelectual de Fernando Pessoa é reconhecido por seus estudiosos por duas características principais: heterogeneidade dos temas e universalidade dos autores. Essas preponderantes marcas estão presentes igualmente em seus textos. Tanto a heterogeneidade quanto a universalidade se apresentam em sua produção pelo desdobramento de sua subjetividade plurimembre nas já catalogadas 136 personalidades fictícias (Pizarro, 2017), que se multiplica em mais de trinta mil textos que compõem o acervo depositado hoje no espólio $\mathrm{E}_{3}$ da Biblioteca Nacional de Portugal. Sua produção aponta para um universo de influências dificilmente catalogável, impossível de ser sintetizado em índices, quer onomásticos quer temáticos, tamanha a variedade de teorias estéticas e filosóficas formadoras do background de Pessoa, sobre o qual já apontava a investigadora Filipa de Freitas: «Não é inédito que Fernando Pessoa teve uma vasta cultura literária nem que a sua relação com outros escritores raiou, frequentemente, a crítica, ora positiva, ora negativa, numa comparação com o seu próprio ideal. A este propósito, basta verificar a sua biblioteca particular, onde se encontram dezenas de volumes [...] destacando-se a literatura [...]» (Freitas, 2016: 117).

A BpFP (Biblioteca Particular de Fernando Pessoa) possui catalogados 1317 volumes, «estando nela representadas oito línguas (Espanhol, Francês, Galego, Grego, Inglês, Italiano, Latim e Português)» (Pizarro et al., 2010:15), títulos que, como se pode verificar on-line (todos os volume da biblioteca estão digitalizados e a grande maioria possui livre acesso) ${ }^{1}$, abrangem todas as áreas de conhecimento, havendo, no entanto, uma concentração maior dos volumes na classe 8 da Classificação Decimal Universal (CDU). Segundo os editores Jerónimo Pizarro, Patricio Ferrari e Antonio Cardiello:

[...] seguindo o sistema de Classificação Decimal Universal (CDU) 10 (v. título de cada classe na lista principal), a classe 8 («Linguística. Filologia. Literatura») contém mais da metade dos volumes, sendo que a classe 1 («Filosofia. Psicologia»), com 181 títulos, ocupa também uma parte considerável do acervo total. A colecção está composta por livros, revistas, jornais e recortes de imprensa adquiridos através de diversos meios: prémios escolares, compras (directas e por correspondência), aquisições em segunda mão, ofertas, heranças, entre outros 11. (Pizarro et al. 2010: 15)

Esse considerável acervo de literatura inclui diversas peças de teatro, que principiam em Sófocles, passando por William Shakespeare, J.W. von Goethe, Molière, culminando em dramaturgos que sobrevieram à Segunda Guerra Mundial. Destacam-se, entre esses mais recentes homens de teatro lidos por Fernando Pessoa, o russo Nicolai Evreinov e o belga Maurice Maeterlinck. A quantidade e, sobretudo, a variedade das correntes estéticas dos autores catalogados na BpFP nos impelem muitas dificuldades na tentativa de estabelecer o referido background literário de Pessoa. Uma delas é mapear as influências destes dramaturgos no processo de criação da poesia dramática de Fernando Pessoa. Aliás, o sintagma «poesia dramática» consiste em si mesmo num problema teórico para os estudos pessoanos.

O acervo pode ser consultado remotamente pelo endereço http://casafernandopessoa.cm-lisboa.pt/bdigital/index/index.htm. 
Antecipa-se a essa dificuldade de mapeamento de possíveis influências a questão em torno de outro problema: determinar o material textual que de fato faz parte do que hodiernamente se denomina teatro de Fernando Pessoa. Assim como parte de sua «obra» - fragmentária, plural, e editada apenas após a morte do poeta em 1935- seu «teatro» ainda está em processo de «redescoberta», de transcrição, de restabelecimento dos textos, de descrição de sua materialidade e de devida catalogação, para então uma posterior organização em edições - críticas ou não-e ulterior publicação.

Há setenta anos essa metodologia de trabalho tem sido imprimida - de maneira mais ou menos criteriosa-pelos investigadores, críticos e editores da obra pessoana, iniciada por Eduardo Freitas da Costa na década de 1950, resultando na publicação da edição princeps dos Poemas Dramáticos (1952), que incluía tão somente $O$ Marinheiro e o Primeiro Fausto. Não são poucos os que se têm lançado ao desafio de editar Pessoa desde então.

Apesar das dificuldades, alguns trabalhos significativos sobre o teatro de Fernando Pessoa têm sido publicados em Portugal e no exterior desde 1952. Pode destacar-se entre esses trabalhos o texto «Algumas peças de ficção ainda inéditas de Fernando Pessoa» (1966), de António de Pina Coelho, que apresenta, entre outras coisas, uma lista com peças inéditas àquela altura, encabeçadas pelo título «Theatro d'Extase» (Coelho, 1966). Segue-se o trabalho de Teresa Rita Lopes Fernando Pessoa et le Drama Symboliste: heritage et creation (1977), investigação que situa a produção de Pessoa em seu diálogo com o drama simbolista, na intenção de prescrutar o gênero dramático na peculiaridade do teatro de Pessoa. O interlocutor de Pessoa é o autor belga Maurice Maeterlinck, mas Lopes também «conversa» Pessoa com outros autores do simbolismo francês (por exemplo, Mallarmé); seguem-se a estes os estudos mais focalizados n'O Marinheiro, peça ainda publicada em vida e, por isso, a mais estudada pelos críticos. Destacam-se os trabalhos de Claudia J. Fischer «Auto-tradução e experimentação interlinguística na génese d'O Marinheiro de Fernando Pessoa» (2012); o artigo de Maria Helena de Moura Neves «O estatuto da linguagem n'O Marinheiro de Fernando Pessoa» (2004); a dissertação de Suely Aparecida Zeoula de Miranda O Marinheiro na poesia de Fernando Pessoa: Porto ou travessia? (2006), e, apenas por uma questão de delimitação momentânea, $O$ marinheiro (de) Fernando Pessoa: Heranças clássicas no drama estático, texto de Thiago Bechara (2018); destaco também o número especial da revista Pessoa
Plural dedicado ao teatro de Fernando Pessoa, publicado pela Brown University: Um Novo Acto no Teatro Pessoano (2018), editado a convite pelo Centro de Estudos de Teatro da Universidade de Lisboa; a recente dissertação de Flavio Rodrigo Vieira Lopes Penteado, intitulada $O$ Teatro da Escrita em Fernando Pessoa (2015), e as últimas edições do teatro de Fernando Pessoa, nomeadamente: Teatro do Êxtase (2010), edição organizada por Caio Gagliardi; e a edição crítica do Teatro Estático (2017), edição de Filipa de Freitas e Patricio Ferrari, a edição do Fausto ${ }^{2}$ (2018), edição de Carlos Pittella, e as edições digitais do Fausto, «Fausto: uma existência digital» (acessível em http://faustodigital.com) e da Trilogia dos Gigantes, projeto finalizado, coordenado por Filipa de Freitas e Jerónimo Pizarro.

Salvaguardada a importância de todos os trabalhos referidos acima, a vertente dramatúrgica de Fernando Pessoa, a exemplo do que também ocorreu com os textos em prosa, e diferentemente do que acontece com a denominada «poesia» - que já é contemplada em maior proporção pelas edições dos últimos vinte anos (2000-2020) - é ainda subinvestigada.

Entre as décadas de 1950 e 1980, o teatro de Pessoa era praticamente desconhecido (com exceção, como já referimos, d'O Marinheiro e do Primeiro Fausto), e a crítica em torno do teatro pessoano se tornou mais constante nos últimos quarenta anos. Alguns fatores contribuíram para essa guinada, dentre eles: $a$ ) a aproximação do teatro de Pessoa ao teatro simbolista de Maeterlinck, feita por Teresa Rita Lopes em seu estudo Fernando Pessoa et le Drama Symboliste: heritage et creation, de 1977; b) a descoberta dos textos metateatrais de Pessoa, quer em escritos de estética e de crítica literária, quer em sua extensa epistolografia, publicados primeiramente por Georg Rudolf Lind (1967), ganhando nos últimos anos edições que tratam separadamente, por exemplo, as apreciações literárias (Bothe, 2013); c) as duas edições do Fausto, de Pessoa, organizadas respectivamente por Colombini (1986) e Sobral Cunha (1988); d) mais recentemente, as edições críticas do teatro de Fernando Pessoa, Teatro Estático e Fausto, assinadas respectivamente por Freitas e Ferrari (2017) e Pittella (2018), que possibilitaram aos estudiosos da obra pessoana tomar contato com a sua produção dramatúrgica.

2 Importante não esquecer que podemos considerar a edição de Pittella como a quarta edição do Fausto pessoano. As demais seriam a edição do «Primeiro Fausto» publicada na edição princeps de Eduardo Freitas da Costa (1952), a edição do Primeiro Fausto de Dúlio Colombini (1986), e a edição de Fausto: tragédia subjetiva, de Teresa Sobral Cunha (1988). 


\section{PESSOA LEITOR DE TEATRO}

Pensar Fernando Pessoa leitor de teatro implica, necessariamente, pensar antes Fernando Pessoa leitor. Este é um aspecto que pode passar desapercebido por muitos críticos da obra pessoana, mas é questão importante proposta pelo crítico Patricio Ferrari ao investigar a marginália produzida por Fernando Pessoa em quase trinta anos de sua atividade literária. Em trabalho publicado em 2008, intitulado «Fernando Pessoa as a Writing-Reader: Some Justifications for a Complete Digital Edition of His Marginalia», Ferrari explica como a leitura atenta de Pessoa, seguida da produção de marginália (que se constitui praticamente como um gênero à parte desde Coleridge) tiveram papel decisivo na formação de Fernando Pessoa como escritor.

The practice of marginalia - a term coined by Samuel Taylor Coleridge for annotating the margins of books - has been a fruitiful modus operandi of numerous writers particularly since the last decades of the eighteenth century. And from his Durban days onwards, Fernando Pessoa's writing life evolved within such a practice; for before the writer he came to be, Pessoa was first and foremost, a reader - a reader with pen in hand. (Ferrari, 2000: 69)

Ainda que a presença de um determinado livro na BpFP, mesmo que datado, não coincida necessariamente com o período em que Fernando Pessoa o leu, e tão-pouco represente uma influência direta e definitiva na obra do poeta, é definitivamente importante considerar - no universo de Fernando Pessoa - o cruzamento de informações relativas ao seu acervo, especialmente em se tratando dos autores de teatro, que em sua biblioteca particular se multiplicam. As reflexões de Pessoa sobre esses autores - quer em marginália, quer em textos de crítica avulsos - parecem sobremaneira decisivas para que se analise a relação entre o Pessoa leitor-escritor de teatro. Emerge aqui mais um problema em torno da referida discussão. Como saber que autores de fato influenciaram Fernando Pessoa, e quais ele apenas leu, sem que suscitassem um impacto significativo no seu background? É possível propor então uma aproximação ao problema em termos de conjuntos, de modo que fique mais fácil a compreensão.

Conjunto A - livros de dramaturgos ou sobre dramaturgos que constam na BpFP - Biblioteca particular de Fernando Pessoa (por exemplo, Ésquilo, Sófocles)
Conjunto B - livros de dramaturgos ou sobre dramaturgos que já constaram na BpFP, e que foram negociados ou perdidos (por exemplo, lbsen, Racine)

Conjunto $\mathrm{C}$ - textos de Fernando Pessoa sobre dramaturgos que figuram ou já figuraram na BpFP (por exemplo, Goethe, Shakespeare)

Conjunto $D$ - textos de Fernando Pessoa que incorporam a proposta estética de dramaturgos que figuram ou já figuraram na BpFP (por exemplo, Maeterlinck, Evreinov)

Conjunto $E$ - textos de Fernando Pessoa sobre dramaturgos que não figuram e não figuraram na BpFP (por exemplo, Vitoriano Braga)

$\mathrm{Na} \mathrm{BpFP}$, encontram-se aproximadamente 50 títulos que incluem peças de teatro e ensaios críticos sobre teatro. Em sua maioria, os ensaios críticos versam sobre as obras de autores que fazem parte do acervo do poeta. Destacam-se, no conjunto de peças de teatro, as três versões do Fausto, de Goethe, duas versões de The Tempest, de Shakespeare - além de uma edição da obra completa do dramaturgo inglês -, três volumes do Teatro de Maeterlinck, incluindo uma edição avulsa da peça Monna Vanna, dois volumes do Teatro de Ésquilo e o Teatro da Alma, de Evreinov. Há ainda volumes sobre teatro isabelino, um volume do Teatro de Sófocles, um volume do Teatro de Eurípides, e as Obras Completas de Molière.

A partir dessa bibliografia, procurar-se-á fazer aqui uma breve exposição a respeito de algumas das obras no âmbito do escopo dos conjuntos «A-E» estabelecidos acima, de modo a elucidar alguns pontos sobre a recepção desses autores por Fernando Pessoa, e o ulterior desenvolvimento de estéticas e temas presentes nas referidas obras.

\section{Ésquilo e a gênese do drama lírico}

A importância da presença de obras dos três mais importantes dramaturgos gregos na BpFP em primeira análise não ultrapassaria o aspecto canônico desses textos, ou seja, o consenso de que ler esses textos diz respeito à herança clássica. Eurípides e Sófocles representam esse cânone, e certamente foram uma leitura valorosa para Pessoa, levando-se em conta o fato de o poeta não ter negociado os livros, como fez com tantos outros. É difícil afirmar com convicção quando Pessoa leu os textos, mas o ano de publicação das edições e as assinaturas de Pessoa em alguns 


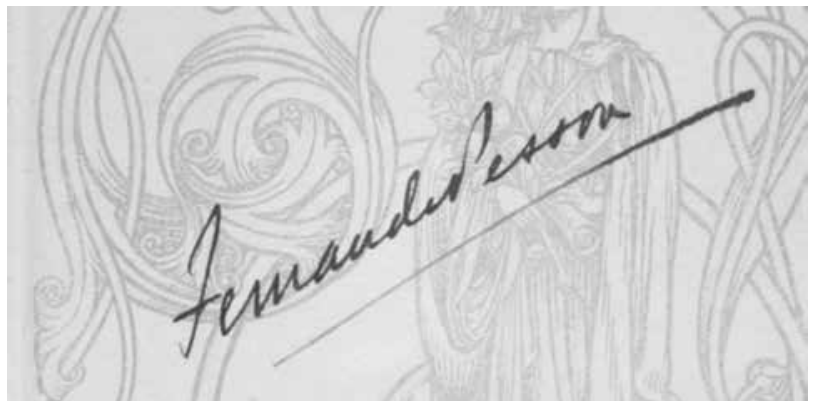

ASSINATURA DE FERNANDO PESSOA, CONTRACAPA DE THE LYRICAL DRAMAS OF ASQUILUS

desses volumes podem auxiliar na tarefa de uma aproximação da datação de leitura pelo autor.

Os textos de Eurípides The works of Euripides (1916), em três volumes, e Théatre de Sophocle (s/d) não apresentam nenhuma assinatura ou datação de Pessoa. Nos três volumes de Ésquilo, Théatre d'Eschyle (s/d) também não constam assinaturas ou datas. Todavia, o volume The Lyrical Dramas of Eschylus (1917) é assinado por Fernando Pessoa. Chama à atenção, sobretudo, a assinatura de Alexander Search, acompanhada da data de dezembro de 1906, na edição francesa, Prométhée enchainé, traduzida por Par H. Weil. A edição é de 1884, mas a assinatura de Search certifica que Pessoa, que provavelmente adquiriu o livro em 1906, o leu após essa data.

As assinaturas de Search e Pessoa nas edições de Ésquilo apontam para a importância do dramaturgo grego na formação do teatro de Pessoa. É possível, contudo, inferir, a partir da data de assinatura de Search, que é coincidente com o período em que Pessoa começou a escrever os poemas do seu Fausto (Pittella in Pessoa, 2018: 24), período também de uma das edições do Fausto, de Goethe, na biblioteca de Pessoa. Esse dado parece corroborar a tese de um crescente envolvimento de Pessoa na leitura de teatro, já que são também de 1908 e 1912, respectivamente, os volumes do teatro de Maeterlinck presentes na BpFP. Ferrari resgata a questão Search-Ésquilo em sua tese de doutoramento Meter and Rhtyhm in the Poetry of Fernando Pessoa (2012):

Aeschylus's Promethée enchainé, a bilingual edition (Greek-French) bears Search's name and date ("December, 1906") on the front flyleaf, as well as the scansion and marginal translation of a few lines [...]. There are a few Greek words in Pessoa's archive, at times with Search's signature accompanying them (e.g., 79A-85'). (Ferrari, 2012: 150)
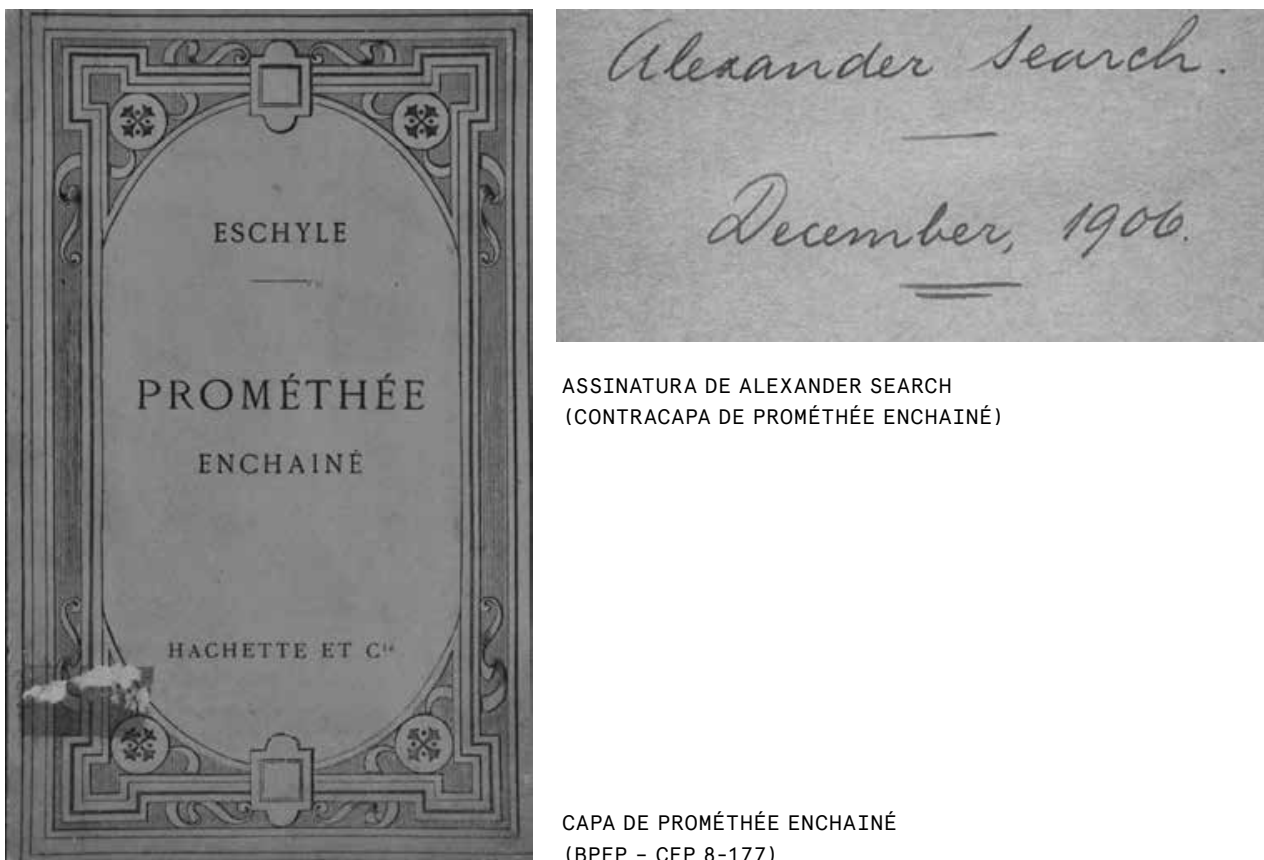

ASSINATURA DE ALEXANDER SEARCH ASSINATURA DE ALEXANDER SEARCH
(CONTRACAPA DE PROMÉTHÉE ENCHAINÉ)

CAPA DE PROMÉtHÉE ENCHAINÉ

(BPFP - CFP 8-177)

Ésquilo também é o criador do que a crítica denominou «drama lírico», gênero que está em alguma medida teoricamente relacionado com o teatro estático, como será apontado mais à frente neste texto. Ainda sobre Ésquilo, há um destaque a lápis, provavelmente feito por Pessoa, no prefácio da edição, na passagem em que o editor, John Stuart Black, introduz a ideia de drama lírico no teatro de Ésquilo.

The lyric drama is the most ancient of all dramatic representation. It is attested that Æschylus composed the music for his own tragedies. That those tragedies were musical throughout there can be no doubt, the dialogue being, as we should now describe it, chanted or intoned upon some pre-scribed arrangement of musical notes, and the choruses which intersperse this dialogue being set to more formal music. This identity of musician and poet, constituting a two-fold "maker", was not continued in the case of subsequent Greek tragedians. (MacFarren, 1880: 126)

Ainda que no nascimento do drama lírico a relação estabelecida seja diretamente entre poesia e música, o papel do coro na tragédia, entre outras características que evoluirão ao longo dos séculos para os autos, os madrigais, os oratórios, e as óperas, a fusão do componente lírico com o drama será de significativa importância para a formação de um 
The academic student, who is familiar with these matters, is aware that what has been here constructed hypothetically, as a natura result of the circumstances, is the real historical account of th
origin and progress of the Greek tragedy, as it is shortly given in well-known passage of Diogenes Laertius. "In the oldest times,"

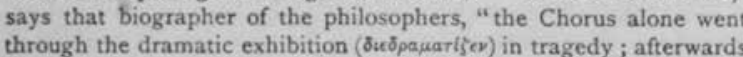
Thespis, to give rest to the Chorus, added one actor distinct from the singers; then Æschylus added a second, and Sophocles a third; which gave to tragedy its complete development." $*$ The reason mentioned here for the addition of the first actor by Thespis, is
a very probable one. The convenience or ease of the singers con. a very probable one. The convenience or ease of the singers con-
tributed, along with the lively wit of the Greeks, and a due regard for the entertainment of the spectators,
step by step, into the lyrical drama.

TRECHO SOBRE LYRICAL DRAMA (THE LYRICAL DRAMAS OF ASQUILUS) (PORMENOR)
Fernando Pessoa dramaturgo, ainda que esse adjetivo, no caso do poeta português, não possa ser tomado em termos categóricos. ${ }^{3}$

Apesar de Fernando Pessoa não ter escrito apreciações literárias direcionadas a Ésquilo, fica claro o interesse do poeta pelo teatro grego, especificamente sobre a relação entre tragédia e a poesia lírica. Há subsídios para que se possa traçar um percurso de leitura de Pessoa, a partir da tragédia ática, na procura de construir um arcabouço que sustente a posterior escritura de seus textos dramáticos.

\section{William Shakespeare e a fusão entre lirismo e simbolismo}

A recepção da cultura literária anglófona por Fernando Pessoa é de uma ordem de grandeza incomensurável, dada não somente a formação inglesa do escritor a partir dos anos de residência em Durban, mas também todo o repertório de autores lidos, traduzidos, comentados e «editados» por Pessoa durante a vida. Na BpFP, encontram-se catalogados mais de 250 títulos em língua inglesa.

Trata-se da biblioteca de um autor português, contudo, atendendo ao facto de a maior parte dos livros estar escrita em língua inglesa, parece antes a biblioteca de um autor inglês que tivesse a necessidade de recorrer a traduções francesas e algum interesse especial pela literatura

3 A esse respeito, é importante referir o ensaio de W. B. Stanford «Sound, Sense, and Music in Greek Poetry» (1981). As relações entre música e poesia são apresentadas pelo autor de maneira categórica, partindo da questão do metro, aprofundando-se, inclusive, na análise dos afetos que são convocados pela música, aspectos tema de reflexão na Antiguidade por parte de Platão e são convocados pela musica, aspectos tema de reflexão na Antiguidade por parte de Platão e
Aristóteles. «[...] we should remember that the Greeks applied the same term to both poetry and music [...] and that Greek poetry at any rate in the earlier periods was probably recited in a semi-musical way, intermediate, we are told, "between singing and speaking". Further, the old name for poetry, before the fifth-century technologists studied it, was "song" [...] (Stanford, 1981: 133). portuguesa. Pessoa comprava livros na Livraria Inglesa de Lisboa e encomendava livros da Inglaterra com alguma assiduidade. Muitos dos títulos portugueses que constam na sua biblioteca foram-Ihe oferecidos, como o revelam diversas dedicatórias. (Pizarro et al., 2010: 14)

William Shakespeare é autor decisivo na formação literária e crítica de Fernando Pessoa, o que pode ser observado não apenas pela presença das obras do autor inglês e de uma considerável bibliografia passiva sobre o autor inglês em sua biblioteca particular, mas sobretudo pelos escritos constituintes de seu espólio nos quais Pessoa dedica boa parte de sua reflexão crítica sobre literatura e teatro em torno das peças de Shakespeare. Além disso, Pessoa foi tradutor do dramaturgo inglês, e em seu espólio encontra-se ainda uma série de planos e listas nos quais os projetos em torno da apreensão crítica e da tradução de Shakespeare faziam parte do horizonte de expectativa do poeta português.

Considerando-se que há uma extensa fortuna crítica em torno da relação Pessoa-Shakespeare, ater-se-á a abordagem aqui proposta a apresentar os pontos mais evidentes da recepção de Shakespeare por Pessoa a partir de sua biblioteca e de suas apreciações críticas ao dramaturgo, em especial àquelas direcionadas especificamente ao teatro.

A presença de Shakespeare, tanto na escrita de Pessoa como na sua biblioteca, ilustra a existência de um diálogo múltiplo e constante com o dramaturgo inglês. Aliás, os quase vinte livros sobre Shakespeare que encontramos na biblioteca pessoana não devem constituir a totalidade dos que o escritor consultou até o fim da vida. (Pizarro/Ferrari, 2011: 66)

A BpFP contém, sob autoria de Shakespeare, uma edição intitulada Obras Completas (s/d), e duas edições de The Tempest, uma de 1908, outra de 1921, respectivamente. Apesar de a edição de Complete Works não ter data de publicação, lemos «F. A. N. Pessoa | With Kind regards from | W[illia]m Storm | Durban | Aug[us]t 16th 1905». Logo, infere-se que Pessoa começou a ler Shakespeare antes mesmo dos demais autores de teatro. Já na segunda página do volume, primeira página de The Tempest, há uma anotação de Pessoa que demonstra o interesse investigativo do poeta em relação ao drama shakesperiano. Pessoa escreve: «First published in the First Folis. 1623» (Shakespeare, s/d: 2). Essas anotações de Pessoa a respeito dos fólios se repetem em primeiras páginas de outras peças ao longo da edição presente na BpFP. 


\section{¿Be Orfors \$baflespeare}

$$
\text { THF. }
$$

COMPLETE WORKS

(1)

WILLIAM SHAKESPEARE

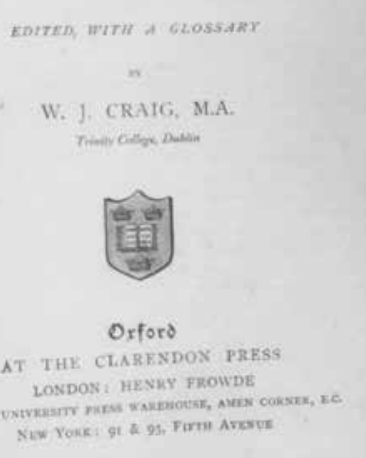

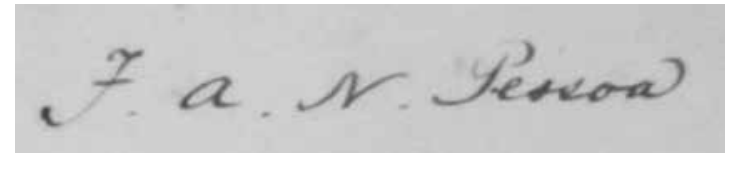

ASSINATURA DE FERNANDO PESSOA, COMPLETE WORKS OF WILLIAM SHAKESPEARE
CONTRACAPA DA EDIÇÃO COMPLETE WORKS OF WILLIAM SHAKESPEARE

O criterioso estudo de Teresa Filipe intitulado «Pessoa, tradutor sucessivo de Shakespeare» (Filipe, 2018: 120-283) corrobora a ideia da presença maciça de Shakespeare em Pessoa. Cita-se ipsis litteris as considerações de Filipe sobre essa atração do poeta pelo dramaturgo.

Pessoa sentiu-se atraído pelo génio de Shakespeare desde muito cedo e sempre ao longo da sua vida. A bibliografia shakespeariana actualmente existente na BpFP é extensa: as obras com data de edição mais antiga são de Walter Begley (1903) Is It Shakespeare? London: John Murray, assinada «Fernando Pessôa», e Thomas Carlyle (1903) Sartor Resartus; Heroes; Past and Present, London: Chapman \& Hall Ltd, assinada «F. A. N. Pessôa» e datada em Durban, «February 1904» (esta obra, não sendo exclusivamente sobre Shakespeare, possui sobre este autor importantes análises, com marginália de Pessoa) e a mais recente, de John Mackinnon Robertson (1930) The Genuine in Shakespeare, London: Routledge Ltd. A esta bibliografia acrescem numerosos documentos autógrafos no Espólio 3 à guarda da Biblioteca Nacional de Portugal onde se encontram registos da presença de Shakespeare em Pessoa, em diários de leitura, planos de tradução, fragmentos. O interesse que o dramaturgo desperta é diversificado, da célebre controvérsia acerca da autoria dos textos shakesperianos a questões relacionadas com a genialidade ou a sua suposta homossexualidade. (Para um estudo e transcrição de documentos sobre «A questão
Fust pultistee, 1602 ; repuntew, 1619 ; appears in the Folis 1623 in The actival state - a new + greality cnlorged vesim, with many

ANOTAÇÃO DE FERNANDO PESSOA SOBRE THE MERRY WIVES OF WINDSOR (BPFP - CDU 821.111-2) (PORMENOR)

Shakespeare-Bacon», ver Fernando PESSOA, Escritos Sobre Génio e Loucura (2006-I: 341-378). O fascínio pela obra do dramaturgo manifestou-se de igual modo na intenção de traduzir as suas obras para português, vontade que o acompanhou nas diferentes empresas de edição que projectou. (Filipe, 2018: 122)

Sobre o trabalho crítico de Pessoa em relação à dramaturgia shakesperiana, além da bibliografia citada por Teresa Filipe, parecem oportunos alguns apontamentos feitos pelo poeta. Em texto conhecido por estudiosos de Pessoa, e atribuído a Ricardo Reis, intitulado «Milton Maior que Shakespeare», Reis compara em escala de gradação Milton, Goethe e Shakespeare, teorizando, dentre outras coisas, sobre o valor do teatro de Shakespeare em comparação ao teatro de Goethe, e afirma:

Ou então a obra de Sh[akespeare] contém mais cousas - outras que psychologicas - do que a de M[ilton]? Mas a de Goethe contém mais que a de S[hakespeare], e G[oethe] não é superior a Shakesp[eare]. Porquê? Porque constróe peor. E o Fausto tem sobre qualquer drama de Sh[akespeare] as vantagens de conter mais ideação romantica, mais intenção de mysterio, mais symbolismo. (Pessoa, 2012: 183).

Esse parece ser um ponto interessante na análise do valor de determinadas características que para Fernando Pessoa compõem o drama do ponto de vista estético, já que uma peça tem «vantagens» sobre outra, por algumas razões, dentre elas conter «mais symbolismo». Na mesma direção, em outros dois fragmentos - estes escritos em inglês - analisa o tipo de dramaturgo que é Shakespeare, caracterizado por uma matéria poética que o diferencia de outros autores de teatro.

Nos fragmentos BNP/E3 [144-54r], «S[hakespeare] either a dramatist, poet or $\mathrm{dr}$ [amatic] p[oet].» - no qual Pessoa escreve, «(c) $\therefore$ [therefore] a lyric poet. [...] Thus we see that the supreme lyric poet ${ }^{*}$ blossoms into the lyrical dramatist.» -, em outro, BNP/E3 [14E- 86] [c.1914], intitulado, «Defects of Sh[akespeare]»- onde se lê: «- The unity of 


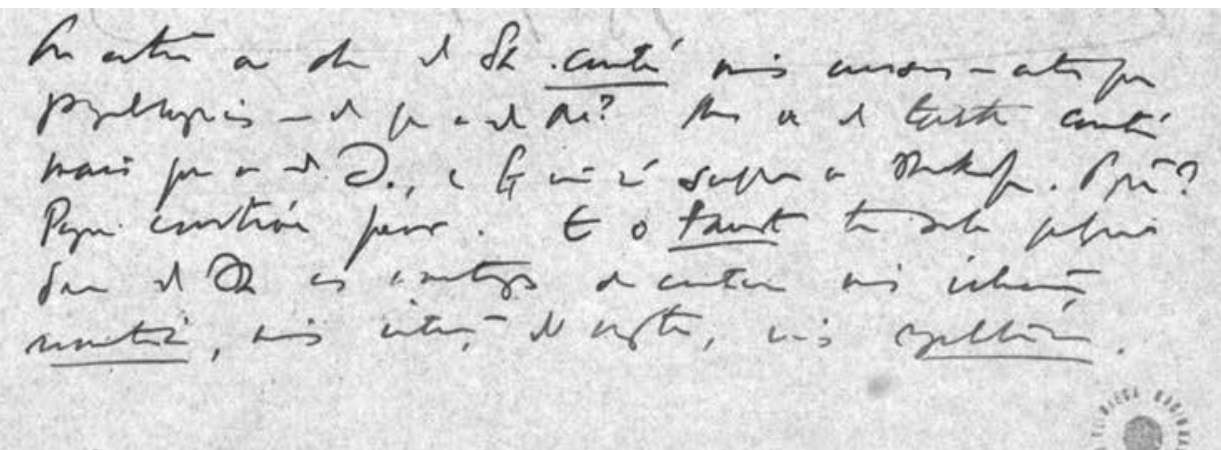

MILTON MAIOR QUE SHAKESPEARE, BNP/E3 [76A-60R] (PORMENOR)

S[hakespeare]'s plays is not dramatic but lyric. [...]»; e, por último, em $\mathrm{BNP} / \mathrm{E}_{3}[76-39]$, «Shakespeare - his defects» - no qual afirma: «O grau supremo do lyrismo será exprimir perfeitamente um grande numero de estados de alma.» (Pessoa, 2012: 236-241) -, percebe-se a dialética construída por Pessoa entre a figura do dramaturgo e do poeta, aprofundando essa dialética para o binômio dramático versus lírico, ainda que aponte que o lirismo, em seu grau «supremo», é capaz de «exprimir perfeitamente grande numero de estados de alma [...]», como citado acima.

Esses fragmentos ratificam uma reflexão constante de Fernando Pessoa sobre a estética do teatro, sobre os elementos que caracterizam um drama e um dramaturgo, e um autor, como Shakespeare, por ser fundamentalmente lírico. Esse perfil, por assim dizer, o afastaria de um modelo de dramaturgo que privilegiaria alguns elementos na constituição de suas peças, a saber pelo fragmento [14E- $85 \mathrm{r}]$, sob o título «Defects of Shakespeare»:

Qualities of the dramatist: A. As to plot:

(1) Completeness.

(2) Inevitableness.

(3) Dramaticness.

(Pessoa, 2012: 239)

José Augusto Seabra, em seu trabalho Fernando Pessoa ou o Poetodrama (1974), já apontava para essa problemática da conceituação de Pessoa como poeta dramático e poeta lírico-dramático (um defeito como em Shakespeare?). Segue explanação de Seabra sobre a questão:
E assim, se Pessoa, enquanto «poeta dramático» (irrealizado), cria os heterónimos, estes, enquanto poetas-outros-que-Pessoa, criam as respectivas obras poéticas. Não é pois, em rigor, o «poeta dramático» que escreve «em» poesia lírica, mas sim os poetas líricos que escrevem, não «em», mas poesia lírica. De facto, não dando Pessoa à poesia dramática «a forma de drama, nem explícita nem implicitamente», restam os poetas líricos a que deu nascença através da sua frustração enquanto «poeta dramático». Pode dizer-se, metaforicamente, que é a morte do poeta dramático que está na origem da sua metamorfose nos poetas líricos, os quais se nutrem da substância do seu corpo múltiplo. (Seabra, 1974: 21)

Poderia depreender-se daí que Pessoa, a exemplo de Shakespeare, é um poeta dramático com os defeitos do excesso de lirismo? Ou trata-se de mais um caso de ironia crítica do poeta? Seria razoável afirmar que Pessoa encarna uma espécie de continuum a partir do qual não seria exatamente um dramaturgo na acepção genética do termo, pois oscila entre a figura do autor de drama, das personagens que compõem esse drama - liricamente $-e$ do espectador de seu próprio drama encenado na subjetividade do autor, e neste último ponto, aparentemente difere de Shakespeare.

Para Pessoa, o elemento lírico seria fundamental para um mergulho no íntimo das personagens, e a forma «verso» em substituição a uma forma mais «narrativa», constitui-se como forma ideal para esse aprofundamento.

Elemento lyrico: (1) aprofundamento da vida interior das personagens: (a) a linguagem, por ser verso, é mais intimamente reveladora de emoção; (b) a circumstancia de o autor imprimir a sua personalidade á expressão que as personagens dão de si (porque fatalmente o verso não varia de person[agem] para personagem, sendo um o estylo - o do autor) dá-lhe a possibilidade de dar toda a emoção possivel, porque a dá atravez do genero de expressão que a sua individualidade busca quando exprime as suas dores;

(c) o caracter das personagens, portanto, de ser vincado mais fundo, para compensar a uniformidade do estylo, não ha aqui outro elemento a apontar?//d'aqui o aprofundamento maior da vida interior da personagem - não é assim?/ (Pessoa, 2012: 241)

Voltando ao início dessa breve abordagem sobre a leitura de Shakespeare empreendida por Pessoa, buscou-se sobretudo demonstrar 
alguns pontos da discussão em torno de uma conceituação sobre dramaturgo, poeta lírico, dramaturgia lírica, dramaturgo lírico. Esse dado importa ao breve estudo em curso porque também diz respeito aos elementos constitutivos de uma metateatralidade em Pessoa, sobre um pensar que se debruça sobre a escrita do teatro e sobre os valores que fundamentarão a sua dramaturgia.

Alguns trabalhos críticos importantes que reiteram a tese da influência de Shakespeare, não apenas na poesia de Pessoa mas também em sua atividade de crítico, deveriam estar presentes, mas deixaram de figurar neste texto por questões de delimitação. Dentre esses trabalhos, convém destacar o trabalho de Mariana Grey de Castro Fernando Pessoa's Shakespeare:The lnvention of the Heteronyms (2015), no qual a esse respeito escreve:

In contrast to the relative scarcity of allusions to Shakespeare in Pessoa's poetry his critical appraisals of the dramatist's work abound, characteristically fragmentary, dispersed and disjointed, and usually in the context of wider examinations on art and literature, authorship, genius and madness, and sexuality. (Castro, 2015: 46)

\section{Nikolai Evreinov e a relação entre teatro e subjetividade}

Os estudos envolvendo a influência de Nikolai Evreinov no teatro pessoano encontram-se em novo estádio após recente publicação do texto de Nicolás Barbosa López «Pessoa e o drama russo: leituras e influências na primeira fase do teatro estático» (López, 2018). De fato, o texto de Barbosa López apresenta, metódica e rigorosamente, elementos da influência de Nikolai Evreinov na formação do teatro estático de Fernando Pessoa. E o faz a partir de pressupostos que são igualmente caros na construção deste presente artigo. A saber, López parte da presença de Evreinov na BpFP, e a partir dessa presença apresenta as aproximações entre o teatro da alma e o teatro estático, ampliando o seu escopo a outros autores do drama russo, especialmente Anton Tchekhov.

A partir de uma das notas de rodapé do trabalho de López, na qual apresenta alguns títulos de teoria teatral escritos por Evreinov, chegou-se a Theatre for Oneself (1915). O argumento central de Evreinov nesse ensaio consiste na ideia que no teatro existe uma figura central, e essa figura central, ela própria, os outros personagens do drama, o conjunto do drama, em última análise, a própria ação, não devem ser considerados como representando alguma realidade objetiva, mas como representando as percepções subjetivas e variáveis da figura central representativa de si e do mundo. Nas palavras de Evreinov:

The art of the "theatre for oneself" is simply an improved or artistically improved edition of that practice in which each of us indulges (for the theatrical instinct is common to all of us) and which is usually defined by rather vague and sometimes not very complimentary expressions, as, for instance, "to play the fool," "to play comedies," "to feign this or that," "to play this or that role," "to watch the fight of two fools, or the quarrel of two lovers". (Evreinov, 1915: 191)

Estabelece-se por ora uma aproximação, ainda que cuidadosa, entre o conceito de «theatre for oneself» de Evreinov e o «drama em gente» de Fernando Pessoa, embora seja consenso entre os estudiosos que, em Pessoa, a ideia do «drama em gente» envolve uma série de aspectos que ultrapassam o problema da dramaturgia em si, enquanto em Evreinov a problematização em torno de autoria e personagens se dá em torno da matéria teatral, ou melhor, do teatro enquanto texto e representação. Contudo, é interessante a ideia do instinto teatral apresentada por Evreinov, na medida em que absorve uma ideia comum em parte do teatro pessoano, a saber, o aspecto metateatral que está presente na ideia de drama em gente, a criar personagens que põem em questão a viabilidade da cena teatral como algo separado da vida.

Oportuno retomar a ideia da paralisia diante da luta entre razão e sensibilidade, entre o objetivo e o subjetivo, entre o lírico e o narrativo, componentes dialéticas do mergulho profundo na individualidade, presentes, segundo Barbosa López, nas peças de Evreinov e Tchekhov (outro autor russo lido por Pessoa e, como Evreinov, presente em sua biblioteca), em consonância como se verá em peças do teatro estático pessoano, mas também no Fausto. Essas componentes, simbolicamente representadas na peça de Evreinov pela estratégia de particionamento e desnominalização das entidades - M1, M2, 1st Concept of Singer, 2nd Concept of Wife -, apontam para o fenômeno do heteronimismo e para estados de alma que tecem o pano de fundo de boa parte da produção em drama escrita por Pessoa, sem mencionar sua decisiva presença no Livro do Desassossego. Destacam-se aqui três fragmentos a ilustrar essa questão (respectivamente, do Fausto, do Desassossego e de Theatre of Soul): 


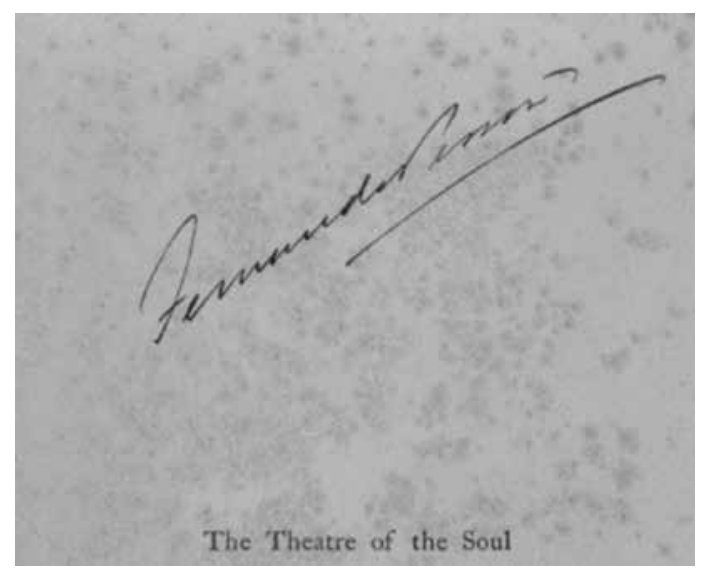

ASSINATURA DE FERNANDO PESSOA, FOLHA DE ROSTO DE THE THEATRE OF THE SOUL

Qualquér cousa maior? Ah deve haver

Além de vida e morte, ser, não ser,

Innominavel super-transcendente -

Eterno incognito e incognoscivel!

Deus? Nojo. Ceo, inferno?

Nojo, nojo. P'ra que pensar, se ha-de parar aqui

$O$ curto vôo do entendimento?

Mais além! Pensamento, mais além!

(Pessoa, 2018: 85)

Sei que estes pensamentos da emoção doem com raiva na alma. A impossibilidade de nos figurar uma coisa a que correspondam, a impossibilidade de encontrar qualquer coisa que substitua aquella a que se abraçam em visão - tudo isto pesa como uma condemnação dada não se sabe onde, ou por quem, ou porquê. (Pessoa, 2013: 390)

M1. Is not you, of course, who are always crying out for brandy. M2. And if I do, isn't forced on me? Isn't it because in your society there is nothing for our poor being to do but hang himself?

M1. Come now! You know very well that it is you, not l, who are the cause of misfortunes. Yes, you, the emotional self. What are you but a selfish libertine, a wreck of a man? Have you ever had any taste for study, ever taken any interest in noble, intellectual work, ever reflected on the ideia of moral dignity?

M2. You are nothing but a pedant, a wretched academic dry-as-dust [...].

(Evreinov, 1915: 17)

\section{LE PLUS VIEIL AVEUGLE.}

Nous ne nous sommes jamais vus les uns les autres. Nous nous interrogeons et nous nous répondons; nous vivons ensemble, nous sommes toujours ensemble, mais nous ne savons pas ce que nous sommes!... Nous avons beau nous toucher des deux mains; les yeux en savent plus que les mains...

TRECHO DE LES AVEUGLES PRESENTE NA BPFP, DESTACADO POR FERNANDO PESSOA (PORMENOR)

A tensão insolucionável entre razão e sentimento, em outras palavras, a impossibilidade de conciliação do pensado e do sentido, no universo de uma vida experienciada, que compreende as dimensões de um dentro e de um fora, e que parece não oferecer nenhuma solução ao impasse pendular de existir em uma espécie de intervalo, apresenta-se como questão presente tanto no drama-poético de Pessoa como no teatro da alma de Evreinov, até porque essa tensão diz respeito à poética de Pessoa em termos mais amplos, mesmo porque ele se autodenominava como «poeta impulsionado pela filosofia» (Pessoa, 1966: 14).

\section{Maurice Maeterlinck, do drama lírico ao teatro estático}

Maeterlinck é o autor mais investigado em termos dialógicos no que diz respeito à concepção e composição dramatúrgica de Fernando Pessoa, especialmente em se tratando do seu teatro estático. A começar com o já citado trabalho pioneiro de Teresa Rita Lopes, vários outros estudos abordam as influências do dramaturgo belga no teatro pessoano, por razões que são definitivamente materiais, e que estão claramente apresentadas no estudo de Erika Brantschen Berclaz intitulado «Fernando Pessoa, leitor de Maurice Maeterlinck: do teatro estático ao drama em gente» (2018).

Duas peças do primeiro volume do teatro estático maeterlinckiano, Les Aveugles e L'Intruse, foram intensamente anotadas pelo escritor português (Maeterlinck, 1911: 199-300 [CFP 8-333])1. A influência direta da leitura 
de Maeterlinck na criação de O Marinheiro (1914) é conhecida (Fischer, 2012). A recente publicação do Teatro Estático pessoano (Pessoa, 2017) possibilita a comparação entre duas visões de uma nova arte total: (i) influenciada pelas artes plásticas; (ii) intimamente associada à poesia lírica; (iii) empenhada no processo de revelação dos mistérios da alma humana; (iv) centrada não na ação dramática, mas na interação entre as personagens. (Brantschen Berclaz, 2016: 42)

Tal qual o procedimento assumido em relação a Evreinov, far-se-á aqui um recorte muito delimitado em relação à leitura que Pessoa faz de Maeterlinck, de modo a evitar o famoso «chover no molhado», perigo iminente nesse caso. Berclaz analisa o tema do estatismo em Pessoa a partir de Maeterlinck, e estabelece conexão desse estatismo com a ideia de drama lírico. E é esse pormenor que interessa nesse momento.

São muitos os textos de Pessoa, incluindo a epistolografia, fragmentos, ou mesmo ensaio de crítica literária e de reflexão filosófica, nos quais o poeta se dedica à reflexão sobre a questão do drama. Em parte desses escritos, estabelece-se um dialogismo entre poeta lírico e poeta dramático, ensaiando por vezes uma possibilidade de síntese que foge aos manuais de conceituação teórico-literária. Em carta escrita em 11 de dezembro de 1931, dirigida a João Gaspar Simões, e publicada postumamente pela primeira vez no n. ${ }^{\circ} 48$ da revista Presença ${ }^{4}$ (julho/agosto de 1931), Pessoa escreve sobre essa difícil síntese que se consubstanciaria em uma entidade nova, inclassificada até então pela teoria literária. Seria ela a do «dramático (sem poeta)». A citação é extensa, mas vale a pena referi-la de modo a ilustrar a divagação a propósito do dialogismo.

O ponto central da minha personalidade como artista é que sou um poeta dramático; tenho continuamente, em tudo quanto escrevo, a exaltação íntima do poeta e a despersonalização do dramaturgo. Voo outro - eis tudo. Do ponto de vista humano - em que ao crítico não compete tocar, pois de nada lhe serve que toque - sou um histero-neurasténico com a predominância do elemento histérico na emoção e do elemento neurasténico na inteligência e na vontade (minuciosidade de uma, tibieza de outra). Desde que o crítico fixe, porém, que sou essencialmente poeta dramático, tem a chave da minha personalidade, no que pode interessá-lo a ele, ou a qualquer pessoa que não seja um psiquiatra, que por hipótese, o crítico não tem que ser. Munido desta chave, ele pode abrir lentamente todas as fechaduras da minha expressão. Sabe que, como poeta, sinto; que, como poeta dramático, sinto despegando-me de mim; que, como dramático (sem poeta), transmudo automaticamente o que sinto para uma expressão alheia ao que senti, construindo na emoção uma pessoa inexistente que a sentisse verdadeiramente, e por isso sentisse, em derivaçõo, outras emoções que eu, puramente eu, me esqueci de sentir. (Pessoa, 1936: 19; grifo nosso)

Esse poeta dramático, que constrói na emoção uma «pessoa inexistente» e finge essa mesma emoção desapegando-se de si próprio, encontra no elemento lírico uma das ranhuras dessa chave codificada que aponta para a fusão de sua «exaltação íntima» com a «despersonalização». G. W. F. Hegel, em um dos seus Cursos de Estética, discorre sobre a lírica, defendendo que, em seu caráter universal, na atitude lírica, o mundo objetivo, subsumido à consciência individual, é absorvido pela interioridade. Essa atividade subjetiva conjura o mundo objetivo, capturando-o para o vórtice (maëlstrom) da vida interior. Afirma-nos Hegel:

Ao separar-se da objetividade, o espírito reclui-se em si mesmo, perscruta a sua consciência e procura dar satisfação à necessidade que sente de exprimir, não a realidade das coisas, mas o modo por que elas afetam a alma subjetiva e enriquecem a experiência pessoal, o conteúdo e a atividade da vida interior (Hegel, 2004: 153-154).

Segundo o filósofo, o que caracteriza, pois, o aspecto lírico da poesia é «a maneira como a alma com seus juízos subjetivos, alegrias e admirações, dores e sensações, toma consciência de si mesma no âmago deste conteúdo» (Hegel, 2004: 177; grifo nosso).

Todo esse léxico, que inclui os termos «alma», «individual», «interioridade», «subjetividade», «âmago», encontra eco nas considerações de Branschten Berclaz: «Em seus textos teóricos Fernando Pessoa valoriza o aspeto lírico do teatro estático» (Brantschen Berclaz, 2018: 49), e de Patrícia Taborda Silva: «Hence, both authors appear to believe that by inhibiting action and focusing on the text they can attain a state which, according to the Belgian playwright, allows the "interior drama" to unfold and the soul to reveal itself (Silva, 2018: 16)», que em seus ensaios tomam a questão sobre o lírico como fundamental para se 
pensar a conexão entre os teatros de Maurice Maeterlinck e Fernando Pessoa.

Na segunda fase de seu teatro, Maeterlinck se afasta do ideal de teatro estático e, assim, procede em certo nível com uma renúncia à tentativa de fusão entre o poeta lírico e o dramaturgo, nas palavras de Marvin Carlson, a partir dessa fase: «a abstração facilmente disponível para o poeta lírico não era possível para o dramaturgo» (Carlson, 1997: 288). Maeterlinck, em seu prefácio ao Théâtre Complet, explicita:

Mais le poète dramatique ne peut se borner à ces généralités. Il est obligé de faire descendre dans la vie réelle, dans la vie de tous les jours, l'idée qu'il se fait de l'inconnu. Il faut qu'il nous montre de quelle façon, sous quelle forme, dans quelles conditions, d'après quelles lois, à quelle fin, agissent sur nos destinées, les puissances supérieures, les influences inintelligibles, les principes infinis, dont, en tant que poète, il est persuadé que l'univers est plein. (Maeterlinck, 1979: 17)

[Mas o poeta dramático não pode se limitar a essas generalidades. Ele é convocado a trazer para a vida real, para a vida cotidiana, a ideia que ele tem do desconhecido. Ele precisa nos mostrar como, de que forma, sob quais condições, a partir de que leis, com que finalidade, agem sobre nossos destinos, os poderes superiores, as influências ininteligíveis, os infinitos princípios dos quais, como como poeta, ele está convencido de que o universo está cheio.]

Acredita-se assim que a poesia dramática de Pessoa é influenciada pela primeira fase da produção de Maerterlinck, e que, anterior ao drama estático, constitui-se a lírica como elemento central na poética dos dois autores, uma espécie de ADN que possibilitará o aparecimento de outras variedades compositivas, principalmente na poética pessoana. Pessoa explana a interdependência entre a ideia de teatro estático e a poesia lírica:

Chamo drama estatico áquelle que, longe de buscar apresentar a acção, pretende apresentar inercias, isto é, que pretende revelar as almas n'aquillo que ellas conteem que não produz acção, nem se revela atravez da acção, mas fica dentro d'ellas, tudo quanto, no bom theatro dynamico, nunca pode apparecer no dialogo. 0 que seria mais normal que a literatura lyrica desse, ou quando muito, a poesia narrativa, no que parte da lyrica - fórma isso a base do theatro estatico. (Pessoa, 2017: 276)
Supponhamos, porén, que o poeta, evitanclo senpre a poesia dramatica, externanente tal, avança ainda wn passo na escala da despersonalização. Certos estados de alma, pensados e não sentidos, sentidos imaginativamente e porisso vividos, tenderão a definir para elle uma pessoa ficticia que os sentisse sinceramente.

OS GRAUS DA POESIA LÍRICA (BNP/E3 18-50R / 18-51R) (PORMENOR)

Avançando ainda na concepção pessoana da poesia lírica, em texto datiloscrito e intitulado «[Os graus da poesia lírica]» (BNP/E3 18-50/51), datado aproximadamente de 1930 e publicado pela primeira no volume organizado por Georg Rudolf Lind, Páginas de Estética e de Teoria e Crítica Literárias (1967), Fernando Pessoa discorre sobre quatro graus de poesia lírica, culminando no grau que aparenta ser aquele atingido por ele na sua incorporação do fenômeno do drama em gente, termo autorreferenciado que será apresentado na carta a Gaspar Simões cerca de um ano depois.

O quarto grau da poesia lyrica é aquelle, muito mais raro, em que o poeta, mais intellectual ainda mas egualmente imaginativo, entra em plena despersonalização. Não só sente, mas vive, os estados de alma que não tem directamente. Em grande número de casos, cairá na poesia dramática, propriamente dita, como fez Shakespeare, poeta substancialmente lírico erguido a dramático pelo espantoso grau de despersonalização que attingiu. [...] Suponhamos, porém, que o poeta, evitando sempre a poesia dramatica, externamente tal, avança ainda um passo na escala da despersonalização. Certos estados de alma, pensados e não sentidos, sentidos imaginativamente e por isso vividos, tenderão a definir para elle uma pessoa fictícia que os sentisse sinceramente [...] (Pessoa, 1930?, BNP/ /E3 18-50r / 18-51r)

Essa indissociável relação entre a lírica e o drama na constituição da poética pessoana já havia sido apontada por Gagliardi e Penteado na coletânea organizada por Ferrari Fernando Pessoa as English Reader and Writer (2012).

Here, the paradox is designed as syllabus: the theater of poetry, the poetry of theater; the play whose features are more lyrical than dramatic, the poem whose features are more dramatic than lyrical. Pessoa's ideal 
of poetic creation, in which the notion of drama is refracted, is guided by a purpose of conjunction based on both the overcoming of clear boundaries between lyrical and dramatic genres and the certainty of the impossibility of giving birth to works perfectly adjusted to the tradition of a genre. (Gagliardi in Ferrari, 2012, p. 174).

\section{J. W. von Goethe e a tragédia subjetiva}

Goethe foi uma influência definitiva na escrita de Fernando Pessoa, e a hipótese levantada aqui é que, mais do que em outros dramaturgos lidos por ele durante a vida, há em Goethe uma espécie de pedra de toque, uma fonte de ideias e conceitos que permeiam parte considerável do conjunto de poemas dramáticos escritos por Pessoa entre 1907 e 1932. Em artigo intitulado «Outros Faustos: as influências da tradição sobre o Fausto pessoano» (2018), é apresentada pela primeira vez, depois da publicação da edição crítica do Fausto de Pessoa, um estudo da influência de Goethe e outros poetas na escrita dos poemas dramáticos que compõem o seu Fausto. Carlos Pittella sugere algumas conexões de uma rede de influências, ao tecer considerações sobre o momento genesíaco do Fausto a partir da materialidade dos suportes usados por Pessoa:

[...] se o poema que editamos como n. ${ }^{\circ} 1$ pode não ser o primeiro, o seu suporte material parece ser o mais antigo. Além disso, ao lado da atribuição «Fausto», o documento ostenta a indicação «Monologo nas Trevas», ecoando o monólogo nocturno da primeira fala do Fausto goethiano.

Foi também em 1907 que Pessoa criou o autor fictício Faustino Antunes [...]. Também data de 1907 uma das edições do Fausto de Goethe na biblioteca pessoana, em tradução francesa, havendo outro volume mais antigo, de 1867, com a tradução inglesa de Anster (os demais volumes pertinentes são de publicação posterior). Ainda, segundo um diário de leituras do poeta (BNP/E3, 28A-1r), foi precisamente em 8 de Maio de 1907 que Pessoa leu Claridades do Sul de Gomes Leal, livro que contém o poema «Fausto e Mephistopheles». (Pittella in Pessoa, 2018: 24)

Goethe é para Pessoa um modelo de escritor tão paradigmático quanto Shakespeare, e aparentemente possui um status diferenciado em relação a outros dramaturgos citados neste artigo. Não parece exagero supor que, além dos poemas componentes do seu Fausto, Goethe tenha influenciado a escrita de outras peças de drama, classificadas ou não no âmbito do teatro estático.

Encontram-se entre os papéis escritos por Fernando Pessoa, 124 textos sobre Goethe, mais de 50 passagens menores, que incluem sublinhados e marginália, e 21 documentos nos quais figuram planos e listas referentes aos Faustos de Pessoa. O volume de documentos reforçam a importância de Goethe como influência na poesia de Pessoa, podendo ser apontados três argumentos fundamentais que sustentam essa influência: a presença de edições das obras de J. W. von Goethe na biblioteca particular; a influência de Goethe na constituição do Fausto português, sustentada pela presença de referências diretas ao autor e à personagem em poemas que compõem o seu poema dramático, além de listas e alguns planos; a considerável gama de papéis encontrados no espólio pessoano cujo tema é Goethe, quer em forma de homenagem, de apreciação literária, de inspiração, e de discussões teórico-filosóficas que versam sobre os temas do gênio, da loucura, da poesia e do drama. No artigo «Outros Faustos: as influências da tradição sobre o Fausto pessoano» (2018), já apontava para essa presença decisiva de Goethe em Pessoa. E ainda que, em comparação com Milton e Shakespeare (e apenas para esses dois), Goethe saísse perdedor, por outro lado, devemos acentuar que «no mundo da crítica pessoana, note-se com quem Pessoa compara, e se verá a gigantesca altura de Goethe e o tamanho de sua influência» (Xavier et al, 2018: 93).

Há certamente outros elementos a serem considerados sobre a influência definitiva de Goethe para a formação literária de Pessoa. Pode, por exemplo, mencionar-se o interesse do poeta em aprender alemão, sustentado pelo «Caderno de Allemão ou de língua parecida $»^{5}$ e o volume presente na BpFP, sob o título German Self-Taught By The Natural Method (1913), que corrobora a hipótese do interesse de Pessoa em ler as obras alemãs na língua original. ${ }^{6}$

5 Disponivel para consulta na Biblioteca Nacional de Portugal: http://purl.pt/13878.

6 Segundo Claudia J. Fischer: «A cerimoniosa epígrafe inscrita na capa do caderno "Em fé de certeza" não deixa dúvidas quanto à sua determinaçăo em aprender o alemão. Quanto à "lingua poéticos ou filosóficos em inglês (que não é obviamente a lingua parecida) e de diferentes exercícios caligráficos da assinatura de Alexander Search o caderno contém uma pásintes exercícios caligráficos da assinatura de Alexander Search, o caderno contém uma página em que
Pessoa faz anotações sistemáticas sobre fonética alemã: o modo como se pronunciam as vogais, comparando-as com as vogais do português, do inglês e do francês, bem como a sua classificação - importante para a escansão de poesia - em vogais longas e curtas» (Fischer, 2010: 8-9). 


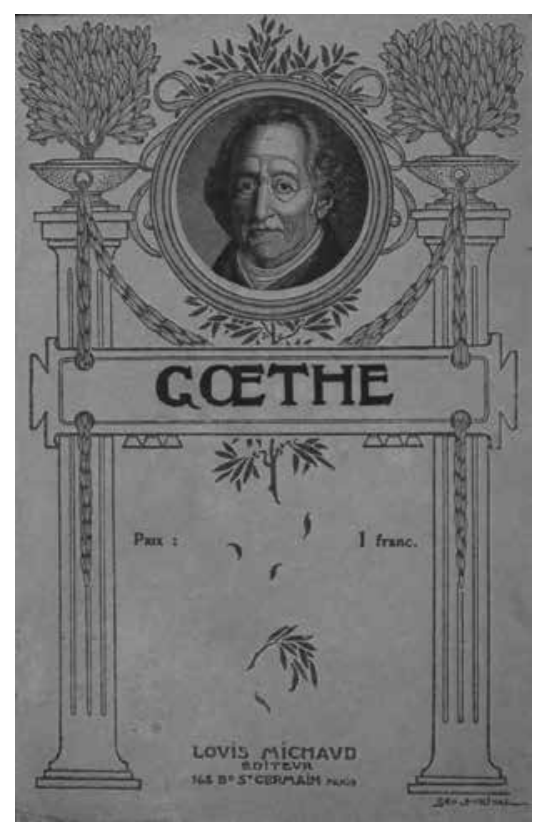

CAPA DE GOETHE: LIEDS; BALLADES;

ODES; ETC (CFP 8-223)

Seguindo essa linha de raciocínio, há na BpFP três traduções do Fausto de Goethe, uma em francês e duas em inglês. 7 Além do Fausto, há na edição em francês os poemas Hermann et Dorothée e a novela Werther. Também conta a BpFP com uma coletânea, igualmente francesa, intitulada Goethe: Lieds; Ballades; Odes; Poésies; Diverses; Sonnets; Épigrammes; Élegies; Prométhée; Divan Oriental-Occidental (1907?); segue-se um exemplar inglês de Conversations of Goethe with Eckermann (1930), texto pelo qual aparentemente Pessoa nutriu um genuíno interesse, levando-o a traduzir um trecho do livro:

Das «Conversações de Goethe com Eckermann»:

Domingo, 3 de janeiro de 1830.

Goethe mostrou-me o annuario inglez, The Keepsake, para 1830, com esplendidas gravuras, e algumas cartas interessantissimas de Lord Byron, que li depois de jantar. Por sua parte, Goethe tinha pegado na ultima traducção franceza do seu Fausto, por Gérard; folheava-a, e de vez em quando parecia ler.

7 «GOETHE, 1867 e 1909a - essas duas edições inglesas contêm a mesma tradução de John Anster; a diferença encontra-se no fato de a edição de 1909 compreender o primeiro e o segundo Faustos de Goethe. A edição de 1867 parece ter tido um dono anterior, apresentando o nome p. 88).

\section{Das "Conversacofes de Goethe com Bokermann":}

Domingo, 3 de Janeiro de 1830

Goethe mostrou-me o annuario inglez, The Keepaake, para 1850, com esplend1das gravures, e algumas cartas interessantiasimas de Lord Byron, que 11 depols de Jantar. Por ana parte, Goethe tinhe pegado na ultiwa tradaogũo Iranceza do geu Fausto, por Gérard; Polheava-a, e de vez om quana parecia ler.

"Watฮึo me passando pela cabeça alguns pensamentos ingularea", disse e1le. "Iste 11vro é agore 11 a numa ño

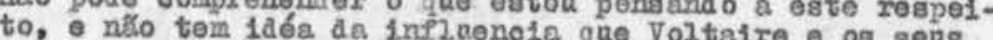
grand es contesmoranoos tiveram na minhs mool omo entro elles governevam todo o mundo olvil1zado. ainha blographia nso mostre olaramente a ineluenol a sos homens na minha mooldade, noz que esforcos mo ong tou - dafender-mo d'ellea e manter o meu proprio terreno num verdadeira, relaģ̃ com a naturoza."

Fallámos mals de Voltalre, e Goethe reoiton-me o seu poema zos systemes, o por ahi comprehend 1 como elle cipio de gne rids.

Blogiou a treduogio de Grrard por muto bem realigada, ainda que prinoipelmente en prose.

"Já nfio gosto", disse, nde ler o mou Fansto om al-

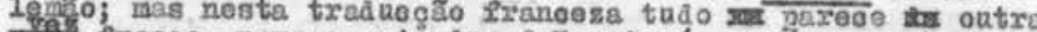
lin Iresao, novo o animado. prasto é, porem, absoluta-

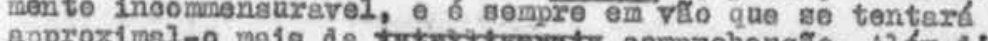
app ouro no indiviano eerto eneanto pare os espiritos hpmonos: trobolhnm

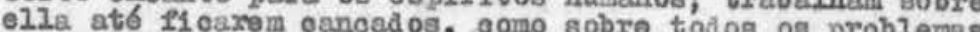
1nsoluve1s •"

(traduzido da traduoção Ingleze de John Oxenford. 
«Estão me passando pela cabeça alguns pensamentos singulares», disse elle. «Este livro é agora lido numa lingua na qual Voltaire dominava ha cincoenta annos. V. não póde comprehender o que estou pensando a este respeito, e não tem idéa da influencia que Voltaire e os seus grandes contemporaneos tiveram na minha mocidade, nem de como então elles governavam todo o mundo civilizado. A minha biographia não mostra claramente a influencia d'estes homens na minha mocidade, nem que esforços me custou o defender-me d'elles e manter o meu proprio terreno numa verdadeira relação com a natureza.»

Fallámos mais de Voltaire, e Goethe recitou-me o seu poema Les Systèmes e por ahi comprehendi como elle deveria ter estudado e assimilado essas coisas no principio da sua vida.

Elogiou ${ }^{8}$ a traducção de Gérard por muito bem realizada, ainda que principalmente em prosa.

«Já não gosto», disse, «de ler o meu Fausto em allemão; mas nesta traducção franceza tudo parece outra vez fresc $0^{9}$, novo e animado. 0 Fausto é, porém, absolutamente incommensuravel, e é sempre em vão que se tentará approximal-o mais da comprehensão ${ }^{10}$. Além d'isso, a primeira parte é producto de um estado um pouco escuro no individuo. Essa propria escuridão tem, porém, um certo encanto para os espiritos humanos; trabalham sobre ella até ficarem cançados, como sobre todos os problemas insoluveis.»

(traduzido da traducção ingleza de John Oxenford.)11

Sunday, January 3, 1830.

Goethe showed me the English Annual, The Keepsake, for 1830, with very fine engravings, and some extremely interesting letters from Lord Byron, which I read after dinner. He himself had taken up the latest French translation of his "Faust", by Gérard, which he turned over, and seemed occasionally to read.

No original <Elegious. Lapso de Fernando Pessoa.

me parece de outra novi [ $\uparrow$ vez] fresco

10 comprehensão

11 James Moorhead (ed.) (1930), Conversations of Goethe with Eckermann, trad. John Oxenford, introd. Havelock Ellis, Londres, J. M. Dent and Sons; Nova lorque, E. P. Dutton and Co. [CFP 8-376].
"Some singular thoughts pass through my head", said he, "on reflecting that this book is now read in a language over which Voltaire ruled fifty years ago. You cannot understand my thoughts upon this subject, and have no idea of the influence which Voltaire and his great contemporaries had in my youth, and how they governed the whole civilized world. My biography does not clearly show what was the influence of these men in my youth, and what pains it cost me to defend my.self against them, and to maintain my own ground in a true relation to nature".

We talked further about Voltaire, and Goethe recited to me his poem "Les Systemes", from which I perceived how he must have studied and appropriated such things in early life.

He praised Gérard's translation as very successful, although mostly in prose.

"I do not like", he said, "to read my Faust any more in German, but in this French translation all seems again fresh, new, and spirited". "Faust", continued he, "is, however, quite incommensurable, and all attempts to bring it nearer to the understanding are in vain. Also, it should be considered that the first part is the product of a somewhat dark state in the individual. However, this very darkness has a charm for men's minds, and they work upon it till they are tired, as upon ali insoluble problems."

E não se restringe o interesse de Pessoa aos textos escritos por Goethe ou, no caso de Eckermann, àqueles em que a sua voz é referida diretamente. Pessoa ainda nutria - assim como acontecia em relação a Shakespeare - um imenso interesse pelos comentadores do poeta alemão. A corroborar essa afirmação, encontram-se na sua biblioteca os volumes: Works of Ralph Waldo Emerson (1902), que conta com o ensaio intitulado «Goethe; or the writer»; The life $\sigma$ Works of Goethe (s/d), assinado por G. H. Lewes; e, finalmente, o texto de Rudolf Steiner L'esprit de Goethe d'aprés Faust et le conte du serpent vert (1926). Embora não figure na BpFP, é provável que Pessoa tenha lido o livro de Alfred Mezières W. Goethe: Les auvres expliquées par la vie (1872), já que possuía um volume do autor sobre Shakespeare, e que figura na lista de livros vendidos-«A[lfred] Mezières:Préd[écesseurs] et contemporainesde Shakesp[eare]. Sold 18-XI-14» (Pizarro et al., 2010: 436) -, e fez alguns apontamentos sobre Goethe a partir do texto de Mezières, o que é possível comprovar 
pelos documentos depositados sob número de cota [134A-82 a 84] e publicados na edição de Jerónimo Pizarro de Escritos sobre Génio e Loucura (Pessoa, 2006). São notas nas quais Pessoa destaca trechos do livro de Mezière sobre o gosto de Goethe pelo mistério, pela independência, e mesmo uma «inadaptação» do poeta à vida social.

Há, no repertório de textos sobre Goethe escritos por Fernando Pessoa, uma abordagem a uma série de temas, por exemplo, a ideia de génio associada a Goethe, a figuração do poeta no hall dos poetas românticos alemães, o diálogo entre Goethe e outros autores referidos nos muitos escritos do espólio pessoano, que inclui Shakespeare, Milton, Byron, Victor Hugo, entre outros.

Em volume que reúne textos de Pessoa sobre Goethe, editado por Nuno Ribeiro e Cláudia Souza, lê-se que o poeta português poderia conhecer outras obras de Goethe além daquelas presentes na BpFP, com base nos textos em que o poeta português «utiliza como contraponto a crítica que Goethe realizou da tragédia Hamlet» (Ribeiro/Souza, 2017:24). Apesar de Ribeiro e Souza estabelecerem juízos de valor em algumas passagens de sua apresentação dos textos - quando, por exemplo, apontam Goethe como «exemplo de excelência estética» (Ribeiro/Souza:31) ou, ainda, quando afirmam veementemente que o texto da cota $\mathrm{BNP} / \mathrm{E}_{3}$, 144-79Ar mostra o impacto que a genialidade de Goethe exerceu sobre o «psiquismo pessoano» (Ribeiro/Souza: 51) -, o volume representa um contributo que endossa o impacto da recepção de Goethe na atividade literária exercida por Pessoa.

Destacam-se alguns pontos de força sobre a influência de Goethe na poesia de Pessoa: as considerações em relação a gênio e loucura; o amplo espectro da produção literária de Goethe; a presença de Goethe nos projetos de Pessoa. Dentre os documentos catalogados no espólio do poeta, cabe destaque ao poema cujo título é «Goethe» (BNP/E3, 29-57r), que integra três das quatro edições do Fausto de Pessoa; o texto «A imoralidade das biografias» (BNP/E3, 19-15r e 15ar); o texto atribuído a Ricardo Reis, intitulado «Milton maior que Shakespeare», no qual Pessoa põe, lado a lado, as obras dos dois poetas ingleses em comparação às obras de Goethe, considerando-as superiores à do escritor alemão; o texto «Psychology of Romanticism», no qual Pessoa disserta sobre a «aspiração romântica», que pode, sem prejuízo semântico ou conceitual, remeter a dois termos intimamente ligados ao primeiro romantismo alemão: streben e senhsucht, o perene tender e o anseio nostálgico românticos, temas reconhecidamente fáusticos.

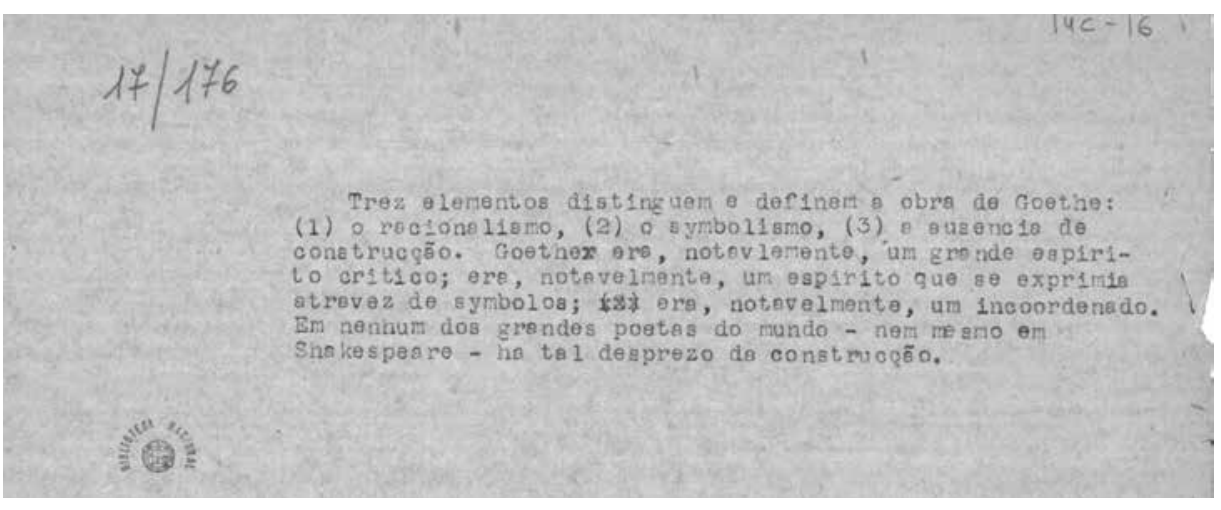

SOBRE O SIMBOLISMO EM GOETHE (BNP/E3 [14C-16R]) (PORMENOR)

Ainda sobre os escritos de Fernando Pessoa sobre Goethe, há textos importantes a destacar, sobremaneira por versarem sobre os temas em questão neste artigo (lirismo, drama, individualidade, tragédia).

\section{a) $\mathrm{BNP} / \mathrm{E}_{3}[14 \mathrm{C}-16]$}

Neste fragmento, Pessoa discorre sobre elementos que definiriam a obra de Goethe. Entre esses elementos elenca o simbolismo, afirmando que Goethe era, apesar de um «grande espirito critico», um «incoordenado». Esse fragmento corrobora a ideia de aproximação entre Goethe e Maeterlinck, já que o teatro estático é sabidamente um gênero que está intrinsecamente ligado à concepção de drama simbolista. Pessoa, em cruzamentos de análise, acaba por encontrar pontos de contato entre os autores que figuram como referência literária desde o início de sua assimilação do tema.

\section{b) $\mathrm{BNP} / \mathrm{E}_{3}[144-71 \mathrm{r}]$}

Esse texto se destaca pela abordagem comparativa que Pessoa faz de Goethe, Shakespeare e Victor Hugo, ratificando que «todos são notáveis no lyrismo» e que Goethe «| tem a intuição do ser lyrico sem ter de si-mesmo |». Reforça-se a força do lirismo a partir da leitura e da crítica sobre Goethe, e soma-se a percepção de uma não-intuição de si-mesmo, que poderia apontar para a ideia de separação entre um sujeito-autor-criador e um sujeito autorreflexivo que não se concebe como tal, inferindo certa cisão no sujeito-Goethe. Seria essa cisão um tema de interesse de Pessoa, que se cindiu em vários, e que de alguma maneira talvez sofresse do mesmo problema que apontava em Goethe, com a diferença de que, segundo Pessoa: «Goethe não se dividiu». 


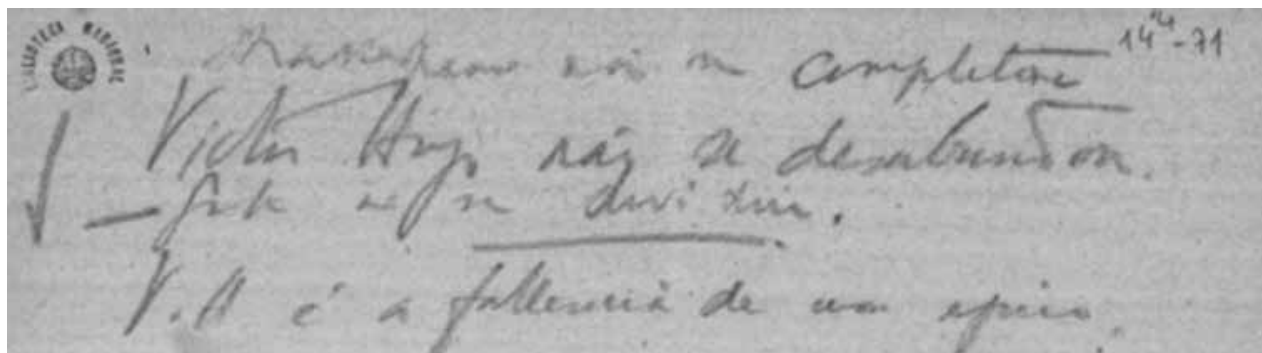

SOBRE LIRISMO DRAMÁTICO EM GOETHE (BNP/E3 [144-71R]) (PORMENOR)

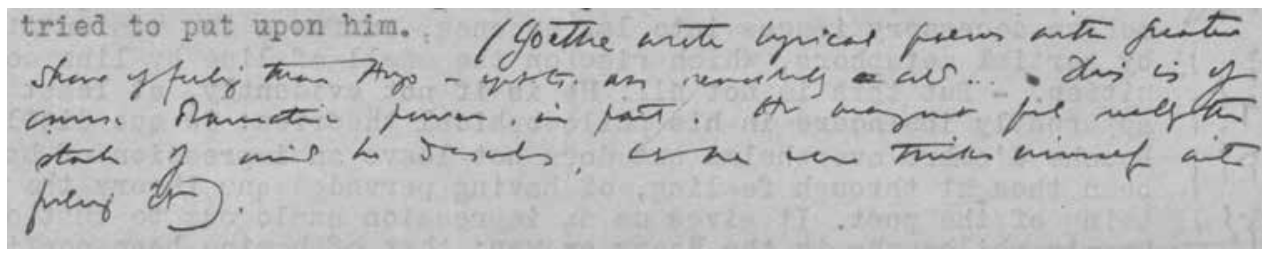

SOBRE LIRISMO DRAMÁTICO EM GOETHE (BNP/E3 [144-71R]) (PORMENOR)

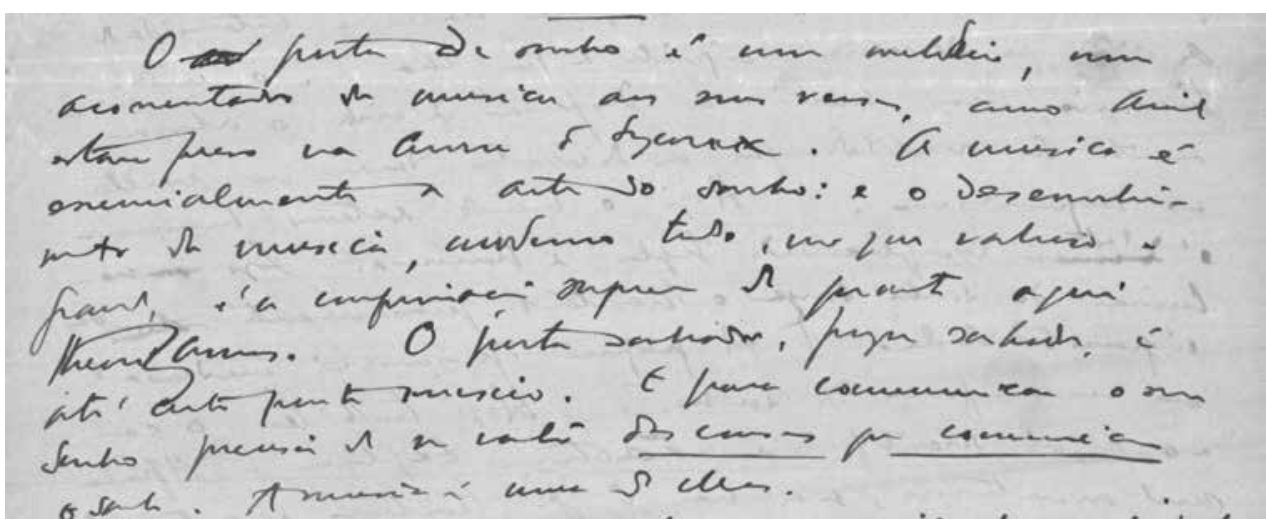

SOBRE FINGIMENTO E TEMPERAMENTO DRAMÁTICO EM GOETHE (BNP/E3 [19-100]R) (PORMENOR)

Shakespeare não se completou

Victor Hugo não se desabundou.

Goethe não se dividiu.

V[ictor] H[ugo] é a fallencia de um epico [...]

\section{c) $\mathrm{BNP} / \mathrm{E}_{3}[19-100]$ e BNP/E3 [143-35]}

Ainda em texto comparativo entre Goethe e Hugo, Pessoa vai mais fundo na presença do lírico na poesia do autor alemão. Goethe escrevia, de acordo com Pessoa, poemas líricos, ainda que fosse um poeta «frio». Essa frieza de Goethe refletiria um poder dramático no autor, que lhe facultaria, por conta desse talento de ser, ao mesmo tempo, frio e lírico, a capacidade de exprimir estados de alma, sentimentos, que ele de fato não sentia, mas que conseguia fingir, porque não sentia, dramaticamente. Ainda sobre a força da lírica, Pessoa escreve no texto Resposta ao Inquérito «O mais belo livro dos últimos trinta anos», publicado pela primeira vez na República, de 7 de abril de 1914: «Posso mesmo acrescentar que a meu vêr, Patria fórma ${ }^{12}$, com o Fausto de Goethe e o Prometeu Liberto de Shelley a trilogia ${ }^{13}$ de grandeza na poesia superlyrica moderna» (Pessoa, 1914: s/p).

Tried to put upon him.

(Goethe wrote lyrical poems with greater show of feeling than Hugo - yet G[oethe] was remarkably cold... This is of course dramatic power, in part. He may not feel really the state of mind he describes, but he can think himself into feeling it)..$^{14}$

\section{d) $\mathrm{BNP} / \mathrm{E}_{3}[19-27$ a 29$]$}

Este último trecho a ser destacado versa sobre a ideia de que é o «sonho» a matéria fundamental da arte moderna. O texto não é especificamente sobre Goethe, mas passeia por vários autores nos quais o sonho é uma questão que põe em contraponto o mundo interior e o mundo exterior, e de que nesse limiar entre interior e exterior reside a impossibilidade, tema recorrente no Fausto, tanto em Goethe quanto em Pessoa. O tema da impossibilidade é objeto de reflexão de Manuel Gusmão em seu penetrante ensaio $O$ Poema Impossível: $O$ Fausto de Fernando Pessoa (1986). No texto, Gusmão discorre sobre os poemas dramáticos que compõem o Fausto de Pessoa, que àquela altura não contava ainda com a sua última versão de 2018 publicada, baseia a sua análise na edição de Freitas da Costa. Se apoia sobretudo na revelação de um conjunto de antinomias irreconciliáveis, e uma dessas antinomias justamente reside na impossibilidade de conjugar o sonho e a realidade, radicalizando essa oposição em oxímoro.

[...] o sonho do intelecto reivindica, por vezes, a verdadeira realidade. Trata-se de uma recusa da exterioridade (lugar de inautenticidade para

que creio que [a meu vêr], a Patria fórma [entra]; [fórma]

[ a forma] a trilogia

14 Fragmento manuscrito na margem esquerda do rosto do documento. 


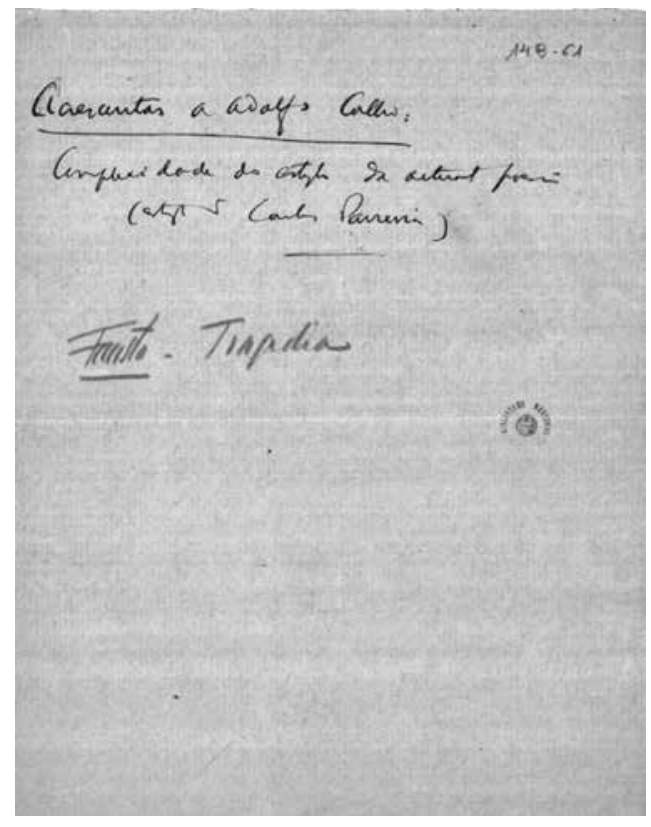

FAUSTO - TRAGEDIA (BNP/E3 [14B-61R]) (PORMENOR)

o sujeito), que nasce de uma outra recusa: aquela que o mundo impõe ao sujeito não se the entregando, sendo-Ihe «inestável», inabitável. [...] Sendo uma ilusão ou uma ficção, o sonho é também a verdade própria em luta contra o não reconhecimento que lhe é imposto. Assim, também a imaginação e apropriação da realidade [...] aparecem como forma de sonho, sempre ameaçado pela exterioridade que é, finalmente, o objecto procurado e não atingido, o lugar onde a verdade se deve, forçosamente, efectivar. (Gusmão, 1986: 65-66).

O poeta de sonho é um melódico, um acorrentado na música dos seus versos, como Ariel estava preso na curva de Sycorax. A música é essencialmente a arte do sonho: e o desenvolvimento da música, moderno todo, no que valioso e grande, é a composição suprema de quanto aqui teorizamos. O poeta sonhador, porque sonhador, é até certo ponto músico. E para comunicar o seu sonho precisa de se valer das cousas que comunicam o sonho. A música é uma d'ellas.

Pessoa no fragmento discorre então sobre o sonho, fazendo um apontamento que conjuga o aspecto lírico, «o poeta ${ }^{15}$ de sonho é um melódico», e o aspecto estático, «O sonho é da vista geralmente. Pouco sabe auditivamente, tactilmente. E o "quadro", a "paisagem" é de sonho, na sua essencia, porque é statica, negadora do continuamente dynamico que é o mundo exterior» (Pessoa, BNP/E3, [19-27v]).

Afinal, há uma infinidade de cruzamentos possíveis entre os textos de Goethe lidos por Pessoa, e a composição de seu Fausto, e de outras peças constituintes de seu teatro. Outras questões poderiam ser aqui levantadas, como a possibilidade do teatro de Pessoa, um teatro como já foi argumentado aqui, fundamentalmente lírico, encontrar linguagem de adesão na performance teatral stricto sensu. O Marinheiro, peça publicada há 105 anos, já foi encenada por várias vezes, ainda que grande parte do teatro de Pessoa continue desconhecida do público. Faltam, naturalmente, condições de uma abordagem sistêmica em se tratando da obra de Fernando Pessoa, todavia cabe o levantamento de uma última questão que conecta Goethe a Pessoa.

É curiosa, e rara, a aparição do termo «tragédia» no corpo das considerações de Pessoa sobre o seu próprio texto dramático. Até à publicação da edição de Carlos Pittella, o Fausto da edição de Teresa Sobral Cunha trazia o subtítulo de tragédia subjetiva. Já é ponto pacífico que esse epíteto atribuído por Sobral Cunha ao Fausto como «totalidade» foi uma escolha editorial da crítica, já que não há certeza em se conectar esse epíteto a um conjunto de projetos, poemas e outros fragmentos que comporiam uma unidade desse fragmentado Fausto. Entretanto, chama a atenção a ocorrência do termo no conjunto de fragmentos pessoanos sobre o Fausto. Carlos Pittella apresenta os documentos nos quais a palavra «tragédia» aparece. Uma das ocorrências está em um plano de intenções de publicação, datado de 1913, e o epíteto «Tragedia Subjectiva» aparece relacionado a «Outro Fausto». Transcrevo o plano a partir da edição de Pittella:

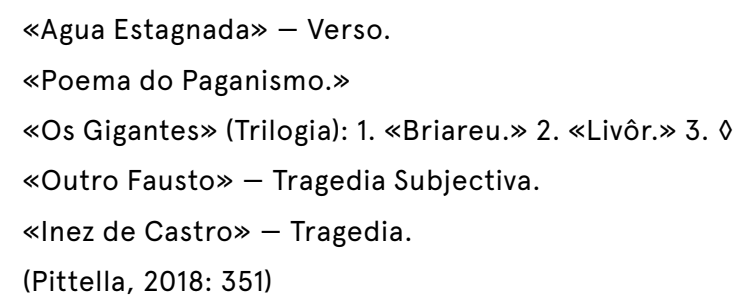

A outra ocorrência do termo «tragédia», conectado ao Fausto, aparece numa nota (BNP/E3 [14B-61r]) com data provável entre 1912 e 1916, já que na parte superior da folha vemos menção a Adolfo Coelho e Carlos 
Parreira, autores que figuram pela primeira vez em textos e correspondências de Fernando Pessoa nesse intervalo temporal.

Infere-se, a partir da ocorrência do termo «tragédia» nos respectivos fragmentos associados ao Fausto - ainda que o Fausto pessoano não tenha sido influenciado apenas pela obra magna alemã -, que o desenvolvimento de uma ideia de tragédia (que nos papéis só vem acompanhada de um adjetivo, «subjetiva») é continente de uma ideia de trágico que pode vir a convergir - sustentada pela leitura ampla e atenta que Pessoa fez de Goethe - com a concepção do trágico em Goethe. Essa ideia tem a ver com uma oposição irreconciliável [unausgleischbar], diz Goethe. Ainda que Goethe não tenha dado a resposta à pergunta que naturalmente surge - Que oposição irreconciliável seria essa? -, a leitura que se impõe aqui é que essa oposição irreconciliável pode dizer respeito às antinomias referidas por Gusmão, por exemplo, entre o mundo do sonho e o mundo real, entre o ser e o existir, entre o querer e o dever, entre o tudo e o nada, entre a inteligência e a emoção, entre a voz e o silêncio, e de fato, essa lista de antinomias no Fausto pessoano é quase interminável e essencial à compreensão do texto dramático pessoano.

Pessoa, desdobrado dramaticamente em heterónimo não atribuído, escreve um texto componente do Livro do Desassossego que talvez ilustre a convergência de temas abordados aqui, trazendo à cena o componente íntimo, quase autobiográfico, que se consubstancia no drama em gente, força centrípeta, redemoinho, maëlstrom, essas tendências em rizoma, que não são capturáveis, e cognoscíveis, talvez, justamente por aquilo que Pizarro chamou de «ansiedade da unidade». ${ }^{16}$

A tragedia principal da minha vida é, como todas as tragedias, uma ironia do Destino. Repugno a vida real como uma condemnação; repugno o sonho como uma libertação ignobil. Mas vivo o mais sordido e o mais quotidiano da vida real; e vivo o mais intenso e o mais constante do sonho. Sou como $\diamond$ um escravo que se embebeda á sesta - duas miserias em um corpo só. Sim, vejo nitidamente, com a clareza com [que] os relampagos da razão destacam do negrume da vida os objectos proximos que nol-a formam, o que ha de vil, de lasso, de deixado e facticio, nesta Rua dos Douradores que me é a vida inteira - este escriptorio sordido até á sua medulla de gente, este quarto mensalmente alugado

16 Jerónimo Pizarro (2016). «A ansiedade da unidade: uma teoria da edição». LEA - Lingue e letterature d'Oriente e d'Occidente, n. ${ }^{\circ} 5$, pp. 284-311. onde nada acontece senão viver um morto, esta mercearia da esquina cujo dono conheço como gente conhece gente, estes moços da porta da taberna antiga, esta inutilidade trabalhosa de todos os dias eguaes, esta repetição $\diamond$ pegada das mesmas personagens, como um drama que consiste apenas no scenario, e o scenario estivesse ás avessas... (Pessoa, $2017)^{17}$

\section{ABERTURA PARA NOVAS DESCOBERTAS EM TORNO DO DRAMA EM PESSOA}

A partir dessa pesquisa, que mostra os primeiros resultados neste texto, abrem-se múltiplas possibilidades de se pensar a arquitetura dos textos dramáticos pesssoanos sob a influência das leituras que o autor empreendeu durante a vida. A Biblioteca Particular presenta indícios, por exemplo, de que Pessoa tenha lido outros poetas-dramaturgos de língua alemã e nórdica, nos quais os temas tratados aqui encontrariam reverberação. Mesmo que em medida menor, esses autores seriam complementares no que diz respeito às ideias de drama lírico, drama subjetivo e drama interior (dentre eles estariam, por exemplo Hofmannsthal e Ibsen - este comprovável o contato por vestígios de obra vendida por Pessoa em uma das listas).

O teatro de Fernando Pessoa ainda está a ser editado, e em breve o teatro não estático, incluindo o que se denomina teatro menor, além de outras peças, como a Trilogia dos Gigantes, será oferecido ao público leitor. Há indícios, pelo contato inicial que se teve com os manuscritos, de que o teatro em processo de edição revela mais pontos de contato entre os elementos que aqui foram analisados como constituintes da escrita dramática pessoana.

Carece, ainda, o presente estudo de um aprofundamento em torno da questão teórica sobretudo em relação aos conceitos de «drama lírico», «teatro estático», «monólogo dramático», a «dramaturgia subjetiva» e a «dramaturgia do eu», esses dois últimos conceitos estudados e desenvolvidos por Peter Szondi em seus textos Theorie des Modernen Dramas (1880-1950) (1965) e Das lyrische Drama des Fin de Siecle (1975). A partir desses textos, e de outros mais recentes, como o ensaio de Jonathan Culler Theory of the Lyric (2015), talvez seja possível pensar

17 Texto disponivel em https://ldod.uc.pt/fragments/fragment/Fr074/inter/Fr074_WIT_MS_ Fr074a_85-86; escrito no verso de dois folhetos «AVISO POR CAUSA DA MORAL» de Álvaro de Campos (Europa, 1923). BNP/E3, 1-83r-84r.1, BNP/E3, 1-83r-84r.2. 
teoricamente o teatro de Fernando Pessoa além dos pares com os quais diretamente dialogou através de seu background.

É possível que o poeta «drama em gente», com sua subjetividade multiplicada em poetas líricos, possa ser considerada trágica na medida em que encarna a goetheana «oposição irreconciliável» (no caso de Pessoa, talvez «oposições irreconciliáveis» seja mais adequado), violenta e desmesurada em sua busca pelo infinito. É o poeta do limite, sua busca é sempre a busca do intangível, por intermédio do indizível. É paradoxalmente na sua fratura que reside sua unidade, mesmo que isso soe estranho aos leitores ainda não iniciados.

\section{REFERÊNCIAS BIBLIOGRÁFICAS}

BARBOSA LÓPEZ, Nicolás (2018), «Pessoa e o drama russo: leituras e influências na primeira fase do Teatro Estático», Pessoa Plural-A Journal of Fernando Pessoa Studies, n. ${ }^{0} 14$, outono, pp. $29-41$.

BRANCHSTEN BERCLAZ, Erika (2018), «Fernando Pessoa, leitor de Maurice Maeterlinck: do Teatro Estático ao drama em gente», Pessoa Plural - A Journal of Fernando Pessoa Studies, n. ${ }^{0}$ 14, outono, pp. $42-58$

CARLSON, Marvin (1997), Teorias do teatro: estudo histórico-critico dos gregos à atualidade, São Paulo, Fundação Editora da UNESP.

CASTRO, Mariana Gray de (2015), Fernando Pessoa's Shakespeare: The Invention of Heteronyms, Londres, Critical, Cultural and Communications Press.

COELHo, António de Pina (1966), «Algumas peças de ficção ainda inéditas de Fernando Pessoa», Brotéria, n.o 83, 10 de outubro, pp. $332-343$.

EVREINOF, Nikolai (1915), The Theatre of the Soul, trad. Marie Potapenko e Christopher St. John, Londres, Hendersons. EVREIN Ov, Nikolai (1927), The theatre in life, Londres, Calcutta, Sydney, George G. Harrap \& Company Ltd.

FER RARI, Patricio (2012), Meter and Rhtyhm in the Poetry of Fernando Pessoa, Lisboa, tese de doutoramento apresentada à Universidade de Lisboa.

FISCHER, Claudia J. (2012), «Auto-tradução e experimentação interlinguística na génese d'O Marinheiro de Fernando Pessoa», Pessoa-Plural. A Journal of Fernando Pessoa Studies, n. ${ }^{\circ}$, primavera, pp. 1-69.

FREITAS, Filipa de (2016), «Fernando Pessoa e o espelho dos poetas», in Monica Lupetti e Valeria Tocco (orgs.), Giochi di specchi Modelli, tradizioni, contaminazioni e dinamiche interculturali nei e tra i paesi di lingua portoghese, Pisa, Edizioni ETS, pp. 117-128.

GUSMÃo, Manuel (1986), O poema impossivel: $O$ «Fausto» de Fernando Pessoa, Lisboa, Caminho.

MAETERLincK, Maurice, (1979), Théâtre Complet, Genebra, Slatkine.

MOORHEAD, James, (ed.) (1930), Conversations of Goethe with Eckermann, trad. John Oxenford, introd. Havelock Ellis, Londres, J. M. Dent and Sons; Nova Iorque, E. P. Dutton and Co.

PESSOA, Fernando (2018), Fausto, ed. Carlos Pittella, Lisboa, Tinta-da-china.

- (2017), Teatro Estático, ed. Filipa de Freitas e Patricio Ferrari, Lisboa, Tinta-da-china.

- (2012), Apreciaç̃es Literárias de Fernando Pessoa, ed. Pauly Ellen Bothe, Lisboa, Imprensa Nacional-Casa da Moeda.

- (2013), Livro do Desassossego, ed. Jerónimo Pizarro, Lisboa, Tinta-da-china.

- (1966), Páginas Íntimas e de Auto-Interpretação, textos estabelecidos e prefaciados por Georg Rudolf Lind e Jacinto do Prado Coelho, Lisboa, Ática.

PIZARro, Jerónimo, et al. (2010), A Biblioteca Particular de Fernando Pessoa, ed. bilingue, Alfragide, Publicações Dom Quixote.
- (2016), «A ansiedade da unidade: uma teoria da edição», LEA - Lingue e letterature d'Oriente e d'Occidente, n. ${ }^{\circ} 5$, pp, 284-311.

- e FERRARI, Patricio (2011), «Uma biblioteca em expansão: Sobrecapas de livros de Fernando Pessoa», Revista Pessoa, n. ${ }^{\circ}$, junho de 2011, pp. 58-96.

SHAKESPEARE, William [s/d], The Complete Works of William Shakespeare, edited with a glossary by W. J. Craig, Oxford, Clarendon Press.

SILVA, Patrícia (2018), «The poetic drama of Fernando Pessoa and W. B. Yeats and the Symbolist Theatre Tradition», Pessoa Plural - A Journal of Fernando Pessoa Studies, n. ${ }^{0}$ 14, outono, pp. $5-28$.

STANFORD, W. B. (1981), «Sound, Sense, and Music in Greek Poetry», Greece $\mho$ Rome 28, n.o 2, pp. 127-40, http:// www.jstor.org/stable/642860.

XAVIER, Rodrigo, BOS, Daniela e PITTELLA, Carlos (2018), «Outros Faustos: as influências da tradição sobre o Fausto pessoano», Pessoa Plural - A Journal of Fernando Pessoa Studies, n. ${ }^{\circ} 14$, outono, pp. 83-119.

\section{RODRIGO XAVIER}

-

Professor Associado do Sector de Literatura Portuguesa do Departamento de Letras Vernáculas da Universidade Federal do Rio de Janeiro e investigador da Cátedra Jorge de Sena para Estudos Luso-Afro-Brasileiros. É mestre em História Social da Cultura e doutor em Letras pela Pontifícia Universidade Católica do Rio de Janeiro (2009), com estágio pós-doutoral em Estudos Germânicos, sob a supervisão de David E. Wellbery, na Universidade de Chicago (2015). Tem contribuído desde 2016 com o professor e crítico Jerónimo Pizarro (Universidad de Los Andes) em projectos de investigação sobre a obra de Fernando Pessoa, com especial interesse sobre a recepção do poeta no Brasil. 